$\mathrm{mg} / \mathrm{L} ; \mathrm{SD} \pm 8,4)$. Association alleles of HLA-A, and DR are depicted in table 1. No association was found with HLA-B alleles.

\begin{tabular}{|c|c|c|c|c|c|c|}
\hline & Patients & Control & Odds Ratio & $\mathrm{Cl}$ & $p$ & $\mathrm{Cp}$ \\
\hline \multicolumn{7}{|l|}{ Resistance } \\
\hline$A^{\star} 28$ & 0 & 11 & 0,0 & $0,0-\mathrm{INF}$ & 0,002 & 0,040 \\
\hline$A^{*} 29$ & 6 & 24 & 0,2 & $0,0-0,6$ & 0,002 & 0,048 \\
\hline \multicolumn{7}{|l|}{ Susceptibility } \\
\hline$A^{*} 68$ & 14 & 2 & 9,9 & $2,1-45,1$ & 0,000 & 0,008 \\
\hline$D R B 1{ }^{*} 01$ & 21 & 5 & 6,4 & $2,3-17,9$ & 0,000 & 0,001 \\
\hline$D R B 1{ }^{*} 04$ & 26 & 11 & 3,6 & $1,6-8,0$ & 0,000 & 0,010 \\
\hline$D R B 1 * 13$ & 24 & 8 & 4,6 & $1,9-11,1$ & 0,000 & 0,004 \\
\hline
\end{tabular}

CHIKV: chikungunya virus infection; $\mathrm{Cl}$ : confidence interval 95\%; $\mathrm{C} p$ : Bonferroni corrected $p$ value.

Conclusions: Our study demonstrated the alleles $A * 28$ and $A * 29$ to be associated with resistance to CHIKV, and alleles $A^{*} 68, D R B 1^{*} 01, D R B 1^{*} 04$ and $D R B 1^{*} 13$ to be associated with susceptibility to CHIKV. No association was found in any HLA-B alleles.

Disclosure of Interest: None declared

DOI: 10.1136/annrheumdis-2017-eular.1887

\section{SAT0576 IMPROVED CLINICAL SCENARIO FOR CHIKUNGUNYA DIAGNOSIS}

J.C. Rueda $^{1}$, J.-I. Angarita ${ }^{1}$, A.M. Santos ${ }^{1}$, E.-L. Saldarriaga ${ }^{1}$,

I. Pelaez-Ballestas ${ }^{2}$, M.J. Soares-Santeugini ${ }^{1}$, J. Londono ${ }^{3}$. ${ }^{1}$ Reumatología, Universidad de la Sabana, Chia, Colombia; ${ }^{2}$ Reumatología, Hospital General de México, México, Mexico; ${ }^{3}$ Reumatología, Universidad de la Sabana-Hospital Militar Central, Bogotá, Colombia

Background: The World Health Organization (WHO) criteria for chikungunya virus infection (CHIKV) have a specificity of $91,1 \%$ with a low sensibility of $56,2 \%$, which decreases the ability to detect patients with the infection. Because of this issue a group of rheumatology, epidemiology and bacteriology experts in diagnosing and treating CHIKV patients performed an agreement consensus on the clinical characteristics of CHIKV infection and proposed a set of clinical criteria. In order to test the performance of the new criteria and improve sensibility and specificity a clinical scenario was developed with the agreements from the expert panel and the clinical characteristics with higher odds ratios.

Objectives: To improve sensibility and specificity of a set of clinical criteria for the diagnosis CHIKV.

Methods: Odds ratios of the clinical features of patients with $\mathrm{CHIKV}$ infection were analysed. A clinical scenario was developed and sensitivity and specificity was calculated.

Results: 37 clinical characteristics were evaluated in a cohort of 604 patients with suspicion of $\mathrm{CHIKV}$. From those, 29 exhibited statistical significance and only 10 had high odds ratios (table 1). A clinical scenario with the following joint involvement (symmetrical arthritis of shoulders or wrists or hands or knees or ankles or feet) or systemic symptoms (fever or rash or myalgia or fatigue) poised a sensitivity of $74,2 \%$ (PPV: $83,5 \%$ ) and a specificity of $88,4 \%$ (NPV: $81,2 \%$ ). The following clinical characteristics extracted from the agreements of the consensus group were added to the clinical picture: origin from an epidemic area and abrupt onset of symptoms.

Table 1. Clinical Characteristics with High Odds Ratios

\begin{tabular}{lccccc}
\hline & \multicolumn{2}{c}{ WHO Confirmed Case Criteria } & Odds Ratio & $\mathrm{Cl}(95 \%)$ & $p$ \\
\cline { 2 - 3 } & $\begin{array}{c}\text { Met Criteria } \\
\text { (n: 150) }\end{array}$ & $\begin{array}{c}\text { Did Not Met Criteria } \\
\text { (n: 454) }\end{array}$ & & & \\
\hline $\begin{array}{c}\text { Symmetry (\%) } \\
\quad \text { Arthritis }\end{array}$ & $80(53,3)$ & $19(4,2)$ & 24,8 & $11,2-54,6$ & $<0,0001$ \\
$\begin{array}{c}\text { Arthritis (\%) } \\
\text { Wrists }\end{array}$ & $16(10,7)$ & $5(1,1)$ & 22,2 & $3,6-204,1$ & $<0,0001$ \\
Hands & $42(28,0)$ & $8(1,8)$ & 36,7 & $8,8-152,6$ & $<0,0001$ \\
Knees & $20(13,3)$ & $5(1,1)$ & 10,0 & $2,8-33,8$ & $<0,0001$ \\
Ankles & $42(28,0)$ & $9(2,0)$ & 24,4 & $7,5-79,3$ & $<0,0001$ \\
Feet & $39(26,0)$ & $8(1,8)$ & 69,3 & $9,6-510,8$ & $<0,0001$ \\
Myalgia (\%) & $106(70,7)$ & $59(13,0)$ & 13,0 & $8,1-20,7$ & $<0,0001$ \\
Fatigue (\%) & $137(91,3)$ & $69(15,2)$ & 16,9 & $10,9-26,8$ & $<0,0001$ \\
Fever (\%) & $150(100)$ & $30(6,6)$ & 13,1 & $8,4-20,5$ & $<0,0001$ \\
Rash (\%) & $109(72,7)$ & $45(9,9)$ & 14,0 & $8,5-22,9$ & $<0,0001$ \\
\hline
\end{tabular}

WHO: World Health Organization; Cl: Confidence Interval.

Conclusions: Our study demonstrated that the proposed clinical scenario for suspicion of CHIKV improves diagnostic sensibility with a slight decrease in specificity, increasing the chance of diagnosis without the need for laboratory tests. We propose that a patient from an epidemic area (fulfilling epidemiological criteria according to the WHO) with an abrupt onset of a clinical picture of symmetrical arthritis of any of the following joints: hands, wrists, shoulders, knees or feet, or the presence of any of the following systemic symptoms: fever, rash, fatigue or myalgia, is more likely to have CHIKV infection.

Disclosure of Interest: None declared

DOI: 10.1136/annrheumdis-2017-eular.1883

\section{SAT0577 MUSCULOSKELETAL MANIFESTATIONS OF TUBERCULOSIS: AN OBSERVATIONAL STUDY}

N. Gupta ${ }^{1}$, A. Bhatnagar ${ }^{2} .{ }^{1}$ Clinical Immunology \& Rheumatology, CHRistian Medical College, VELLORE; ${ }^{2}$ Pulmonology, Rajan Babu Tuberculosis Hospital, Delhi, India

Background: Data of musculoskeletal manifestations of tuberculosis is limited to case reports, series or retrospective study. To our knowledge there is no prospective study which has addressed this issue. So, we conducted this study to create awareness among the doctors about musculoskeletal manifestations of tuberculosis.

Objectives: To study the musculoskeletal manifestations of tuberculosis.

Methods: It was a prospective observational study which was conducted at a referral Tuberculosis Hospital in North India in the month of September \& October 2016. Patients from outpatient and inpatient department of pulmonology were recruited irrespective of the duration of anti tubercular therapy.

We included patients who had active tuberculosis as per World Health Organization (WHO) 2010 criteria. Patients with other chronic illnesses were excluded. A detailed history, examination and appropriate investigations (blood, urine, serological and radiological) of the 100 consecutive patients fulfilling the inclusion criteria was recorded

Results: Mean age of patients was $32.16 \pm 12.93$ years. Male to female ratio was 43:57. Mean duration of disease was $6.85 \pm 8.83$ months. Of the 100 patients, $60(60 \%)$ had pulmonary tuberculosis. Pleural tuberculosis presenting as pleural effusion was seen in $17(17 \%)$ patients. Abdominal tuberculosis was seen in 9 (9\%), tuberculous lymphadenopathy in $8(8 \%)$ and pott's spine in $4(7 \%)$. Eye tuberculosis and tubercular breast lump was seen in 1 patient each.

$83(83 \%)$ patients had first episode of tuberculosis while the other $17(17 \%)$ patients had second episode of tuberculosis. $74(74 \%)$ patients were on category 1 anti tuberculosis treatment (ATT), while $23(23 \%)$ were on category 2 ATT and $3(3 \%)$ were on modified ATT. Mean duration of ATT was $1.79 \pm 1.34$ months.

Fibromyalgia was classified in $21(21 \%)$ patients, polyarthralgia's were seen in 9 $(9 \%)$, pott's spine in $7(7 \%)$, osteomyelitis in $4(4 \%)$ and scleritis in $2(2 \%)$ patients. Uveitis, tenosynovitis, erythema induratum, subcutaneous abscess and dactylitis was seen in $1(1 \%)$ each. Rheumatological manifestations as septic arthritis, DILE, poncet's arthritis, tendinopathy, amyloidosis, gout, erythema nodosum and myositis were not seen in any patient.

In 21 patients who had fibromyalgia, 11 patients developed fibromyalgia with 2nd episode of tuberculosis amounting to $60.75 \%$ patients.

Conclusions: This is the first prospective study to look at the musculoskeletal manifestations of tuberculosis. Patients with active tuberculosis were found to have various rheumatological manifestations.

Acknowledgements: I acknowledge Dr Sushil Gupta, director of the Rajan Babu TB Hspital for allowing me to conduct this study

Disclosure of Interest: None declared

DOI: 10.1136/annrheumdis-2017-eular.1357

\section{SAT0578 LEFLUNOMIDE INHIBITS THE APOPTOSIS OF HUMAN EMBRYONIC LUNG FIBROBLASTS INFECTED BY HUMAN CYTOMEGALOVIRUS}

Q. Ren ${ }^{1}, \mathrm{H}$. Zeng ${ }^{2} .{ }^{1}$ Department of Pediatric Allergy, Immunology and Rheumatolog; ${ }^{2}$ Department of Pediatric Allergy, Immunology and Rheumatology, Guangzhou Women and Children's Medical Center, Guangzhou, China

Background: The immunomodulatory drug leflunomide (LEF) is frequently used for treating human cytomegalovirus (HCMV), but its antiviral mechanism is still unclear.

Objectives: In this study,we therefore investigated the effects of the active LEF metabolite A771726 on the HCMV lifecycle in human embryonic lung fibroblasts. We clarified the mechanism of LEF antiviral infection, and provide a new way to treat immune dysfunction patients with HCMV infection.

Methods: The experiment was divided into four groups:the control group, the HCMV group, the ganciclovir + HCMV group as well as the LEF + HCMV group. MTT was usedfor assessmentof the cell inhibitory rate. Apoptosis was measured by staining with fluoresceinisothiocyanate Annexin $\mathrm{V}$ and propidium iodide. Statistical significance was determined by paired $t$-test using SPSS software.

Results: The results of the study showed that cell proliferation was significantly inhibited by HCMV at 24 hours and 48 hours. With increasing HCMV concentration, the value-added inhibition of the cells was significantly decreased compared with the control group, and was statistically significant $(P<0.01)$. Ganciclovir can increase proliferation of cellsinfected with $\mathrm{HCMV}$;compared with the control group it was statistically significant $(P<0.05)$. Meanwhile,with LEF treatment cell proliferation was significantly improved at 24 hours and 48 hours, with statistical significance $(P<0.05)$. The apoptosis rate of human embryonic lung fibroblasts infected with HCMV increased significantly at 24 hours, 48 hours and 72 hours, and as time goes on the apoptosis rate increases statistically significantly $(P<0.01)$ compared with the control group The apoptosis rate of theHCMV infection group decreased by adding LEF, and was statistically significant $(P<0.05)$.

Conclusions: In this studywe show that LEF is an exciting new drug for cytomegalovirus infection. LEF significantly inhibited HCMV infection-induced apoptosis and proliferation, playing an important role in the treatment of patients infected by HCMV. In this study we explored the potential usefulness of LEF for 